\title{
Influence of Angulation in Cervical Prosthetic Emergences Relative to the Gingival Tissue of Teeth Treated under the Biologically Oriented Preparation Technique (BOPT)
}

\author{
Amaia Amesti-Garaizabal ${ }^{1}$, Rubén Agustín-Panadero ${ }^{2, *}{ }^{\circledR}$, María Fernanda Solá-Ruíz ${ }^{2} \mathbb{D}$, \\ Lucía Fernández-Estevan ${ }^{2}\left(\mathbb{D}\right.$, Xabier Amezua-Lasuen ${ }^{3} \mathbb{D}$ and Jorge Alonso Pérez-Barquero ${ }^{2}$ \\ 1 Private Practice, 48001 Bilbao, Spain; aamesti005@ikasle.ehu.eus \\ 2 Department of Stomatology, Faculty of Medicine and Dentistry, University of Valencia, 46010 Valencia, Spain; \\ m.fernanda.sola@uv.es (M.F.S.-R.); jorape2@uv.es (J.A.P.-B.); lucia.fernandez-estevan@uv.es (L.F.-E.) \\ 3 Department of Graphic Design and Engineering Projects, Gipuzkoa Faculty of Engineering, University of the \\ Basque Country UPV/EHU, 20018 San Sebastián, Spain; xabier.amezua@ehu.eus \\ * Correspondence: ruben.agustin@uv.es
}

Received: 8 May 2020; Accepted: 10 June 2020; Published: 15 June 2020

\begin{abstract}
Background: The objective of this study was to digitally evaluate the effect of the cervical emergence of restorations in terms of gingival tissue volume. Materials and methods: In this study, 31 upper front teeth (from canine to canine) were selected and prepared using the biologically oriented preparation technique (BOPT). Each tooth had undergone a change in its provisional process with different emergence profile angles: $30^{\circ}$ and $60^{\circ}$. Each sample was digitalised (STL file) using an intraoral scanner. By using various pieces of manipulation software for STL files, a volumetric analysis protocol was carried out. Changes in gingival thickness and position were measured at the buccal and the lingual positions. Results: By increasing the angulation of the emergence profile to $60^{\circ}$, the gingival thickness increased by $0.255 \pm 0.381 \mathrm{~mm}(p=0.001$; $t$-test $)$ at buccal and by $0.038 \pm 0.381 \mathrm{~mm}$ at lingual ( $p=0.600$; $t$-test). In relation to the gingival height, at buccal, there is an apical displacement of $0.262 \pm 0.246 \mathrm{~mm}(p=0.001 ; t$-test), and at lingual, there is an apical displacement of $0.390 \pm 0.279 \mathrm{~mm}(p=0.001$; $t$-test). It was shown that an increase in the provisional emergence profile angle significantly diminishes the gingival height while significantly increasing gingival thickness. The Pearson's correlation coefficient, $r=0.636$, was moderately high and significant ( $p=0.001$; Pearson). Conclusions: The soft tissue surrounding the BOPT restored tooth evolved according to the prosthetic emergence angle of the provisional restoration, enabling us to plan for an apico-coronal and bucco-lingual displacement of the gingival tissue prior to the definitive restoration.
\end{abstract}

Keywords: BOPT; interim; emergence profile; provisional restoration; periodontal tissue

\section{Introduction}

The digital work-flow in dentistry has increased in recent years due to technological advances in intraoral scanners and software. Intraoral scanners can digitalise the oral cavity and create a virtual three-dimensional model; the individual images obtained are stitched together with other ones, and the result is a mesh of points that creates a three-dimensional (3D) virtual model of the object being scanned [1,2].

Recently, superimposition and comparisons of 3D digital images have been used to measure the volume and contour changes in various fields of dentistry. This process can be described as an objective 
method to quantify three-dimensional changes and achieve a precise measurement and volumetric reconstruction [3].

A healthy relationship between dental restorations and the periodontium is of fundamental importance to ensure clinical success in both the function and esthetic harmony of full coverage restorations. One of the most common complications derived from fixed prostheses is gingival recession, which constitutes an important clinical concern. This problem is largely associated with the iatrogenic effects produced during dental preparation or as a result of a poor prosthetic fit; it will compromise esthetics, and thus is particularly detrimental in the anterior region. Subgingival horizontal preparations have been conventionally indicated in cases of aesthetic demand; however, they are related to adverse periodontal reactions, such as inflammation, bleeding, deeper probing, and recession [4].

The biologically oriented preparation technique (BOPT) is a protocol whereby vertical preparation eliminates the anatomical emergence profile of the crown corresponding to the cement-enamel union (CEJ) to create a new emergence with a prosthesis that imitates the natural tooth at the very moment it is positioned. The protocol for the manufacture of the provisional prosthesis is of key significance as it determines the new emergence context, placing it at different levels within the gingival sulcus. This allows the surrounding soft tissue to adjust its form and position to accommodate the new prosthetic profile, thereby guiding the healing, the reinsertion, and the thickening of the gingival tissue [4-8].

It has been suggested that thicker soft tissue biotypes are associated with less tissue recession, higher crestal bone levels, and better aesthetics. A thin tissue biotype has been shown to be more prone to tissue recession. Furthermore, there is evidence that thick soft tissue may be protective against crestal bone loss. As a result of these findings, many authors have recommended the routine use of connective tissue grafts to thicken the labial soft tissue to $>2 \mathrm{~mm}[9,10]$. This is an important clinical finding because, traditionally, soft tissue grafts have been used to enhance the thin soft tissue, to thicken the buccal bone and crestal labial soft-tissue around teeth and implants, and vice-versa [11].

The authors who have published on the BOPT technique have detected a clinical thickening of the gingival tissue and a soft tissue stability improvement around dental restorations $[4,7,8]$, but the measurement mechanisms used by these authors have been subject to variation. It was also noted by these authors that this technique enables gingival tissue to be displaced in an apico-coronal and bucco-lingual direction, thereby modifying the cervical emergence of the tooth-supported prosthesis.

The objective of this study was to digitally evaluate the effects of cervical emergence in the gingival tissue volume and thereby quantify and objectively outline the modifications taking place in the gums. The established hypothesis was that a change in the angulation of the cervical emergence of the BOPT prosthesis would modify the incisal position of the gingival margin and the thickness of the adjacent gingiva.

\section{Materials and Methods}

The sample consisted of 31 patients who gave their informed consent. This study was approved by the Clinical Research Ethics Committee (CEIH) of the University of Valencia, Spain with the procedural registration number H1510309932301. All patients were treated between September 2017 and September 2018 in the Prosthetics Clinic, Department of Dentistry, Faculty of Medicine and Dentistry at the University of Valencia.

The inclusion criteria were being over the age of 18 , being a non-smoker, being periodontically healthy or monitored, and having experienced previous treatments with a fixed prosthesis (unitary crowns in the upper front quadrant) with the need for substitution of that prothesis. 


\subsection{Dental Preparation (BOPT)}

A total of 31 previous restorations were withdrawn (incisives and upper canines), one for each patient, and these teeth were prepared using BOPT (Figures 1 and 2) [6]. The clinical sequence for BOPT was as follows: Before the removal of the old restorations, double probing (gingival sulcus probing and bone probing) was performed to determine the preparation limit and to situate the location of the provisional restoration (0.5-0.8 $\mathrm{mm}$ below the edge of the gingiva) so as not to invade the supracrestal attached tissue. After the removal of the old restorations, BOPT preparation eliminated the pre-existing finish line using a turbine and 100/200 $\mu \mathrm{m}$ cone diamond bur with a $1.2 \mathrm{~mm}$ diameter (862.534.012, BOPT drills; Sweden and Martina, Due Carrere, Padua, Italy). For realization of the BOPT preparation technique, the bur was first introduced with an angulation of $10-15^{\circ}$ with respect to the dental axis. This first step aimed to open the dental groove and eliminate the first millimetre of the emergence of the anatomic crown. In the second step, the bur was introduced parallel to the dental axis in order to eliminate the pre-existing finish line. In the third and final step, the bur was introduced at a 3-6 angle with respect to the dental axis to give it the necessary convergence (Figure 3). Afterwards, in accordance with the protocol guidelines, a provisional crown was made in the clinic for each tooth with self-polymerizing acrylic resin (Sintodent, Sintodent s.r.l., Roma Italy) with an approximate angle of $45^{\circ}$. The provisional prosthesis created a new cement-enamel-prosthetic junction situated in the gingival sulcus at a depth of $0.5-0.8 \mathrm{~mm}$, with consideration of the biological width. Provisional restorations were not removed until the soft tissues had completely matured-a period of 8-12 weeks.

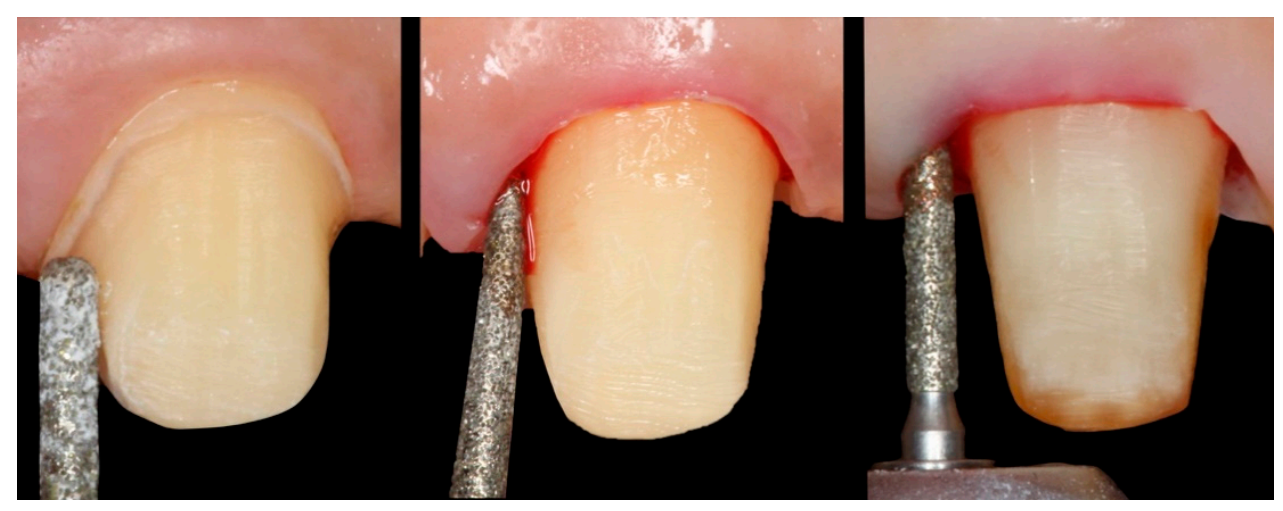

Figure 1. (a) Tooth with a chamfer finishing line. $(\mathbf{b}, \mathbf{c})$ tooth being prepared with the BOPT technique.

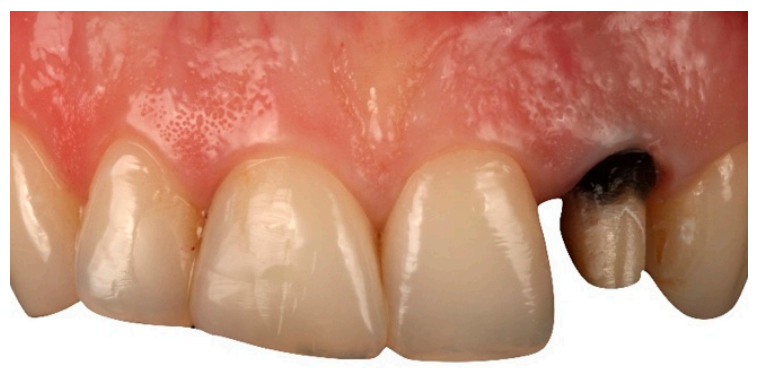

(a)

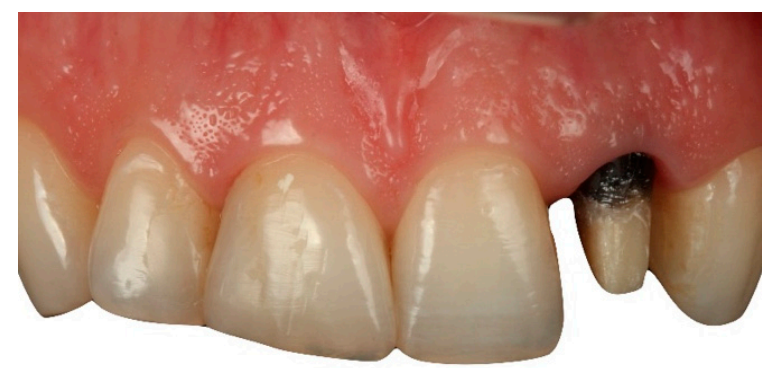

(b)

Figure 2. (a) Tooth after restoration being removed, with a chamfer finishing line. (b) Tooth after biologically oriented preparation technique (BOPT) preparation technique. 


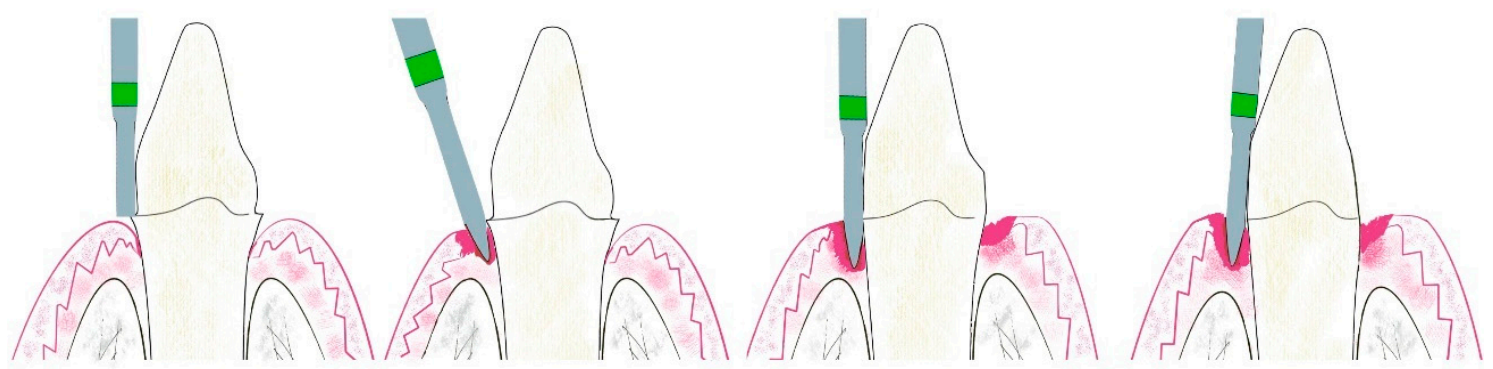

Figure 3. (a) Tooth with chamfer finishing line. (b) Bur with an angulation of $10-15^{\circ}$ with respect to the dental axis. (c) Bur parallel to the dental axis. (d) Bur with an angulation of $3-6^{\circ}$ with respect to the dental axis.

\subsection{Impression Technique and Provisional Process}

Next, impressions were taken with the virtual gingiva protocol described by Agustín-Panadero et al. [12]. For this, the stumps and the provisionals were taken out of the mouth, and the cemented provisionals were scanned using an intraoral scanner (True Definition; 3M TM). The 3D geometries obtained in the different scans were aligned using the best fit between common surfaces in reverse engineering software (Geomagic Studio; Geomagic Inc.); in that same software, the virtual gingiva was obtained by means of a boolean algorithm, thereby avoiding collapse of the gingiva. From this virtual gingiva, the prosthetist created two provisionals using CAD/CAM (ExoCAD GmbH, Darmstadt, Germany) for each patient with different angulations of the emergence profile: $30^{\circ}$ and $60^{\circ}$ (Figure 4).

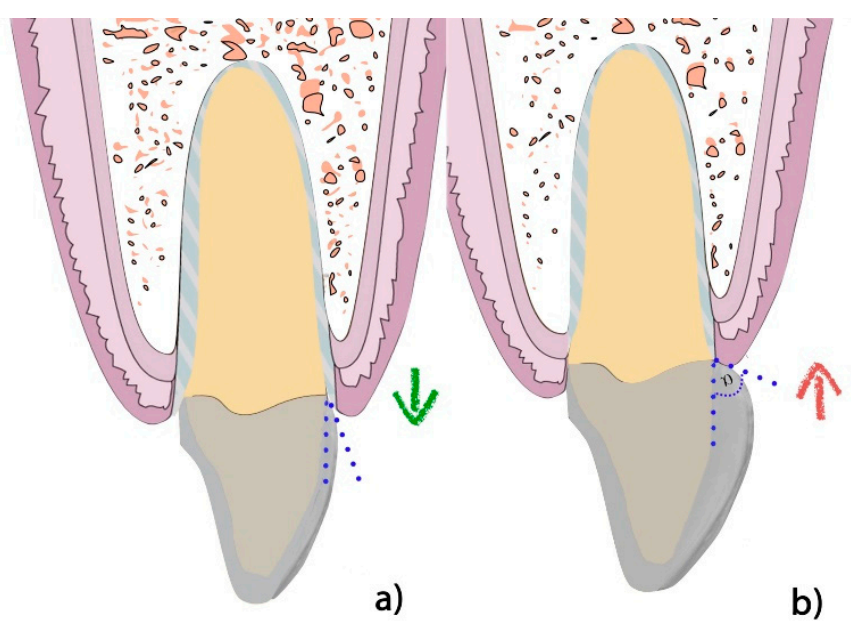

Figure 4. (a) Provisional with a $30^{\circ}$ emergence profile. (b) Provisional with a $60^{\circ}$ emergence profile.

Once the provisional restorations were ready, each patient underwent a change of the provisionals, starting with the $30^{\circ}$ provisional that was cemented. At 2 weeks, the situation of the gum was monitored (Figure 5). After this stage, the said provisional was removed, and a $60^{\circ}$ provisional was put into place; similarly, at 2 weeks, the tissues surrounding the crown were checked (Figure 6). Each step was scanned and analysed according to the three-phase method described below. 


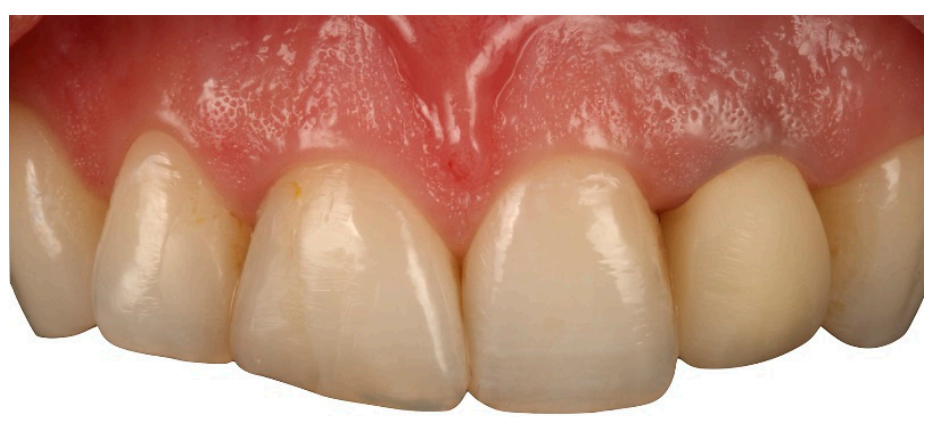

Figure $5.30^{\circ}$ provisional crown after 2 weeks of healing.

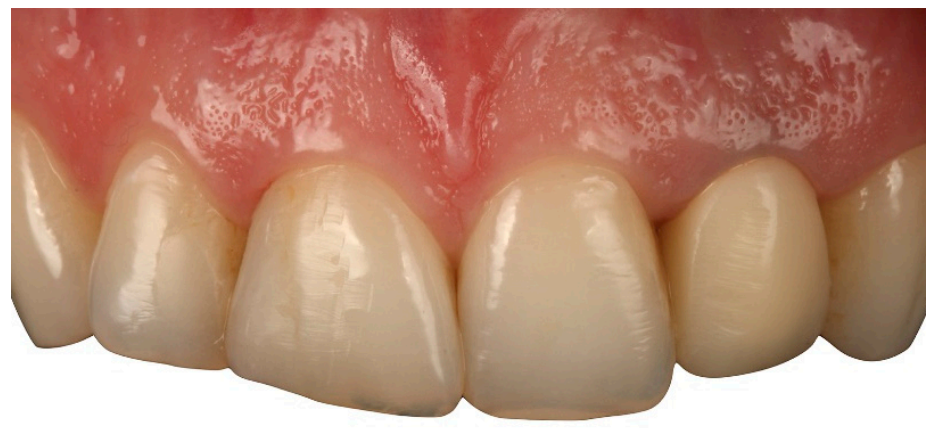

Figure $6.60^{\circ}$ provisional crown after 2 weeks of healing.

\subsection{Change of Provisionals and Scans}

Both the internal and external portions of the $30^{\circ}$ provisional were scanned outside the oral cavity using an intraoral scanner (True Definition; $3 \mathrm{M}^{\mathrm{TM}}$ ), thereby obtaining the STL_30 file. (Figure 7a).

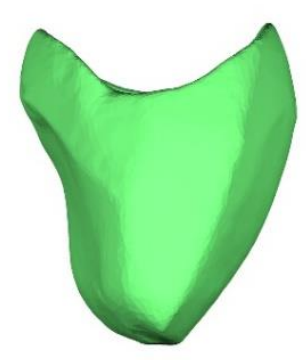

a)
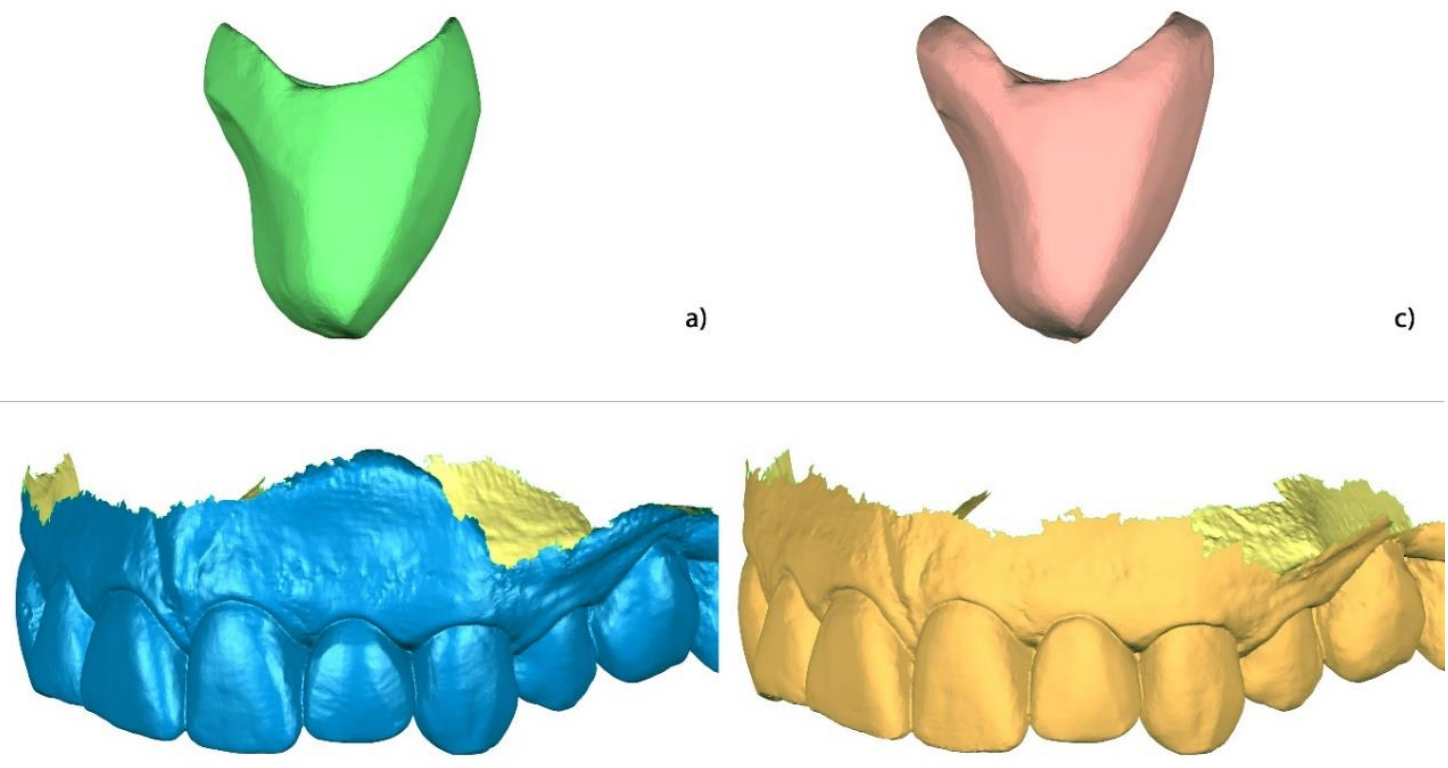

b)

d)

Figure 7. Geometries in 3D obtained in the different scans: (a) $30^{\circ}$ provisional (STL_30), (b) $30^{\circ}$ provisional cemented after 2 weeks in the mouth (STL_30_arch), (c) $60^{\circ}$ provisional (STL_60), and (d) $60^{\circ}$ provisional cemented after 2 weeks in the mouth (STL_60_arch). 
The $30^{\circ}$ provisional was cemented (Temp Bond Clear, Kerr Dental, Orange, CA, USA), and 2 weeks later it was scanned together with its adjacent teeth, thereby obtaining the STL_30_arch file (Figure 7b).

Both the internal and external portions of the $60^{\circ}$ provisional were scanned outside of the oral cavity using an intraoral scanner (True Definition; $3 \mathrm{M}^{\mathrm{TM}}$ ), thereby obtaining the STL 66 file (Figure 7c).

The $30^{\circ}$ provisional was removed, and in its place, a $60^{\circ}$ provisional was cemented; 2 weeks later, it was scanned together with its adjacent teeth, thereby obtaining the STL_60_arch file (Figure 7d).

In this first phase, 4 STL models were obtained; these corresponded to the 2 provisionals scanned outside of the oral cavity with their complete contouring (STL_30 and STL_60) and their position once cemented in the oral cavity together with the teeth and adjacent gingival tissue structure after 2 weeks (STL_30_arch and STL_60_arch).

\subsection{Alignment of the 3D Geometries Obtained in the Different Scans in Consideration of a Global Coordinate System}

The STL_30 file was imported into reverse engineering software (Geomagic Studio; 3D Systems, Rock Hill, South Carolina, USA), and three reference points were created: the apical buccal point (B), the apical lingual point (L), and the incisal point (I) (Figure 8a). Once those 3 points were created, a plane through the 3 points was drawn up, thereby obtaining Plane B-L.

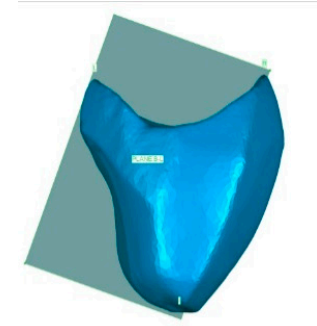

a)

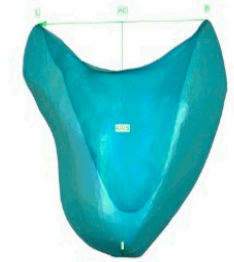

b)

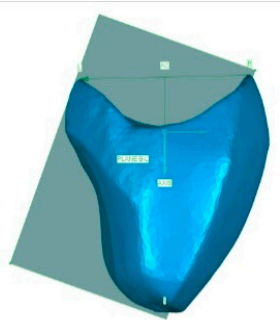

Figure 8. Alignment of the $3 \mathrm{D}$ geometry of the $30^{\circ}$ provisional in relation to the global coordinate system. (a) Plane B-L was created through the B, L, and I points. (b) The axis was created through the $\mathrm{AC}$ and I points. Note that the transparency of the provisional offers a better view of the Axis. (c) Plan B-L becomes parallel to the global XY coordinate system plane, and the tooth's axis becomes parallel to the $\mathrm{Y}$ axis of the global coordinate system.

To establish the tooth's axis, 2 points were selected. The first was the incisal point (I). To create the second point, a line that linked point $\mathrm{B}$ and point $\mathrm{L}$ was created; using a mathematical calculation, the software devised a point located at the centre of this line, thereby obtaining the apical centre point (AC) corresponding to the mid-point between point B and point L (Figure 8b). Once points I and AC were established, a line that united them (AXIS) was created, thereby corresponding to the tooth's axis.

Making use of the software, the plane created in step 4 (plane B-L) was aligned with plane XY of the global coordinate system, whereby the AXIS line coincides with axis Y (Figure 8c).

The file corresponding to the $30^{\circ}$ crown cemented together with its adjacent teeth (STL_30_arch) was imported into the software, and the alignment was made through the best-fit algorithm with the STL_30, which was oriented with respect to the coordinate axis in the previous step. For this purpose, the common surfaces in both $3 \mathrm{D}$ geometries were selected, i.e., the surfaces of the $30^{\circ}$ provisionals (Figure 9a,b). 


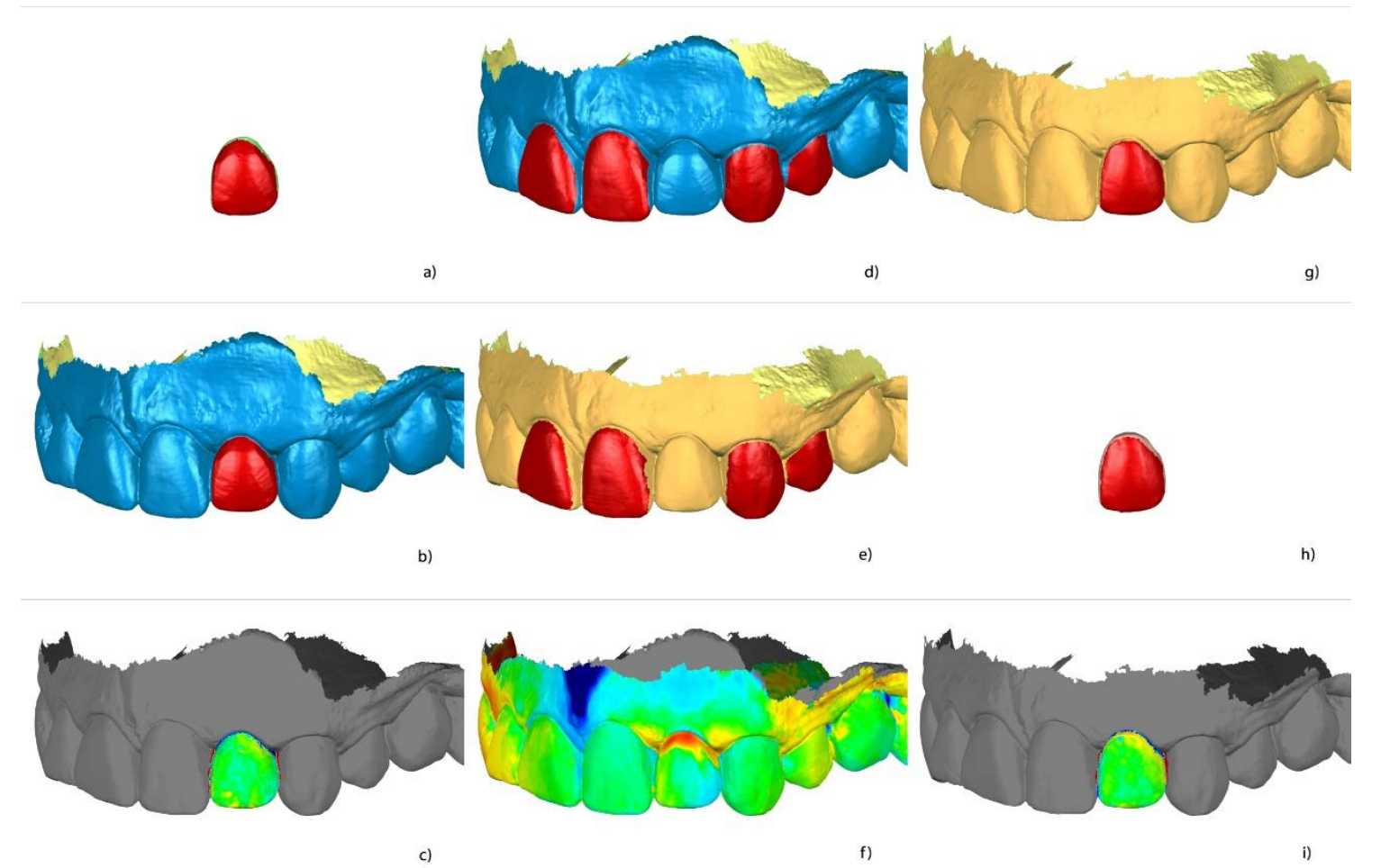

Figure 9. (a) selection of the supragingival area of the $30^{\circ}$ provisional in the STL_30 file. (b) Selection of the supragingival area of the $30^{\circ}$ provisional in the STL_30_arch file to attain a correct alignment. (c) Comparison of the quality of the alignment between the STL_30 file and the STL_30_arch file. (d) Selection of the teeth adjacent to the provisional presenting no changes during the treatment in the STL_30_arch file. (e) Selection of the teeth adjacent to the provisional presenting no changes during the treatment in the STL_60_arch file. (f) Comparison of the quality of the alignment between the STL_30_arch file and the STL_60_arch file. (g) Selection of the supragingival area of the $60^{\circ}$ provisional in the STL_60_arch file. (h) Selection of the supragingival area of the $60^{\circ}$ provisional in the STL_60 file. (i) Comparison of the quality of the alignment between the STL_60_arch file and the STL_60 file.

The quality of the alignment was checked by carrying out a three-dimensional comparison (Figure 9c), where the green colour denotes a correct alignment.

The STL_60_arch file corresponding to the $60^{\circ}$ crown cemented together with its adjacent teeth was imported into the software, and then the alignment was made with respect to the STL_30_arch file, thereby attaining alignment with the global coordinate axis in step 8 using the best-fit algorithm. For this purpose, the common surfaces in both 3D geometries were used, i.e., the surfaces belonging to the adjacent teeth (only the dental surfaces, omitting the interproximal areas, as these, together with the soft tissues, are usually areas that generate much noise when using intraoral scanners) (Figure 9d,e).

The quality of the alignment was checked via a three-dimensional comparison (Figure 9f), where a green colour denoted a correct alignment. A red area indicated that a change had taken place, corresponding in this case to a change of the provisional $30^{\circ}$ crown to the $60^{\circ}$ crown.

File STL_60 was imported into the software, and, by applying the best-fit algorithm, it was aligned with the file STL_60_arch. For this purpose, the common surfaces in both 3D geometries were used, i.e., the surfaces belonging to the $60^{\circ}$ provisional, while taking the precaution of omitting non-coinciding areas corresponding to occlusal adjustment surfaces adjoining lingual surfaces (Figure 9g,h).

The quality of the alignment was checked via a three-dimensional comparison (Figure 9i), whereby the green colour denoted a correct alignment.

Each geometric alignment was exported from the software in the STL format. After the first 13 steps, a common alignment of the 4 files was obtained. These results were, in turn, aligned with a 
global coordinate system: The Y-axis coincided with the longitudinal axis of the tooth, and the X-axis with the buccal-lingual axis.

\subsection{Analysis of the Results}

The aligned files, STL_30,STL_30_arch, STL_60, and STL_60_arch, were imported into inspection software (GOM Inspect; GOM GmbH, Braunschweig, Germany), and a section coinciding with plane $\mathrm{XY}$ was created (Figure 10).

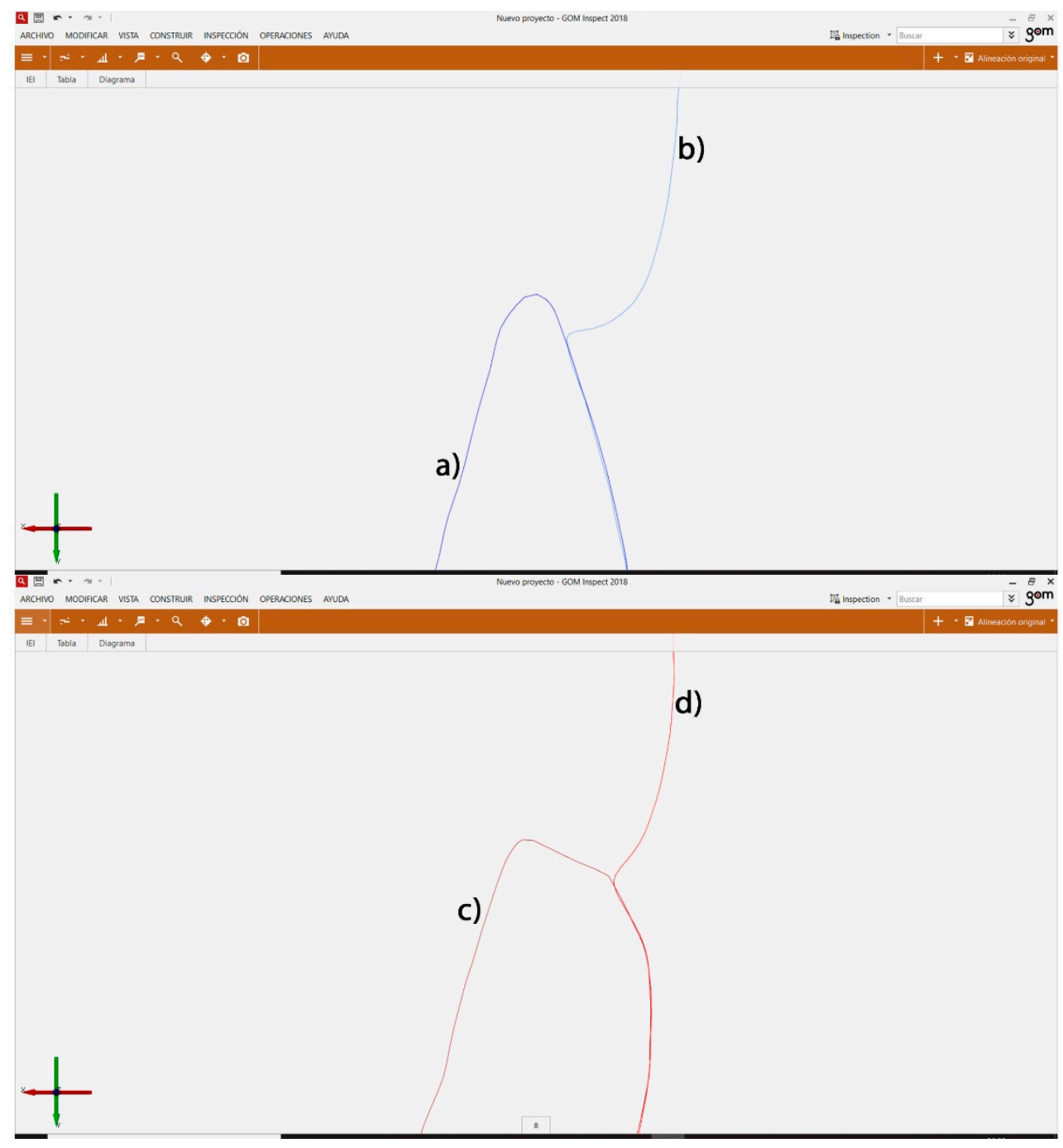

Figure 10. (a) Detail of the buccal aspect of the STL_30 section. (b) Detail of the buccal aspect of the STL_30_arch section. (c) Detail of the buccal aspect of the STL_60 section. (d) Detail of the buccal aspect of the STL_60_arch section.

In the inspection software, the following points were defined on the section: the most apical point of the provisional crown (corresponds to where the prosthetic CEJ should be located, precisely at the interface between the sulcular epithelium and the inserted epithelium) in the STL_30 section (1B) and in lingual (1L) and the crossing point between the buccal STL_30_arch gum section and the STL_30 provisional crown section (2B) and in lingual (2L) (Figure 11a).

Two lines along the $X$ coordinate system direction were created: one that passed through point $1 \mathrm{~B}$ (Line_1B) and another that passed through point 1L (Line_1L). Furthermore, two Y coordinates system direction lines were created: one that passed through point 2B (Line_2B) and the other that passed through point 2L (Line_2L) (Figure 11b). 
Point 3B was created automatically; this point was located at the intersection of Line_1B and the buccal aspect of the STL_30_arch section, and point 3L was situated at the intersection point of Line_1L and the lingual aspect of the STL_30_arch section (Figure 11b).

Point $4 \mathrm{~B}$ was created automatically and corresponds with the intersection point between Line_1B and Line_2B; point 4L is the intersection point between Line_1L and Line_2L (Figure 11b).

The following measurements were made:

Gingival thickness in buccal: Distance from point 1B to point 3B, THICKNESS_B_30 (Figure 11d).

Gingival thickness in lingual: Distance from point 1L to point 3L, THICKNESS_L_30 (Figure 11c).

Gingival height in buccal: Distance from point 2B to point 4B, HIGH_B_30 (Figure 11d).

Gingival height in lingual: Distance from point 2L to point 4L, HIGH_L_30 (Figure 11c).

Steps 11-14 were repeated for the aligned geometries of the files STL_60 and STL_60_arch.
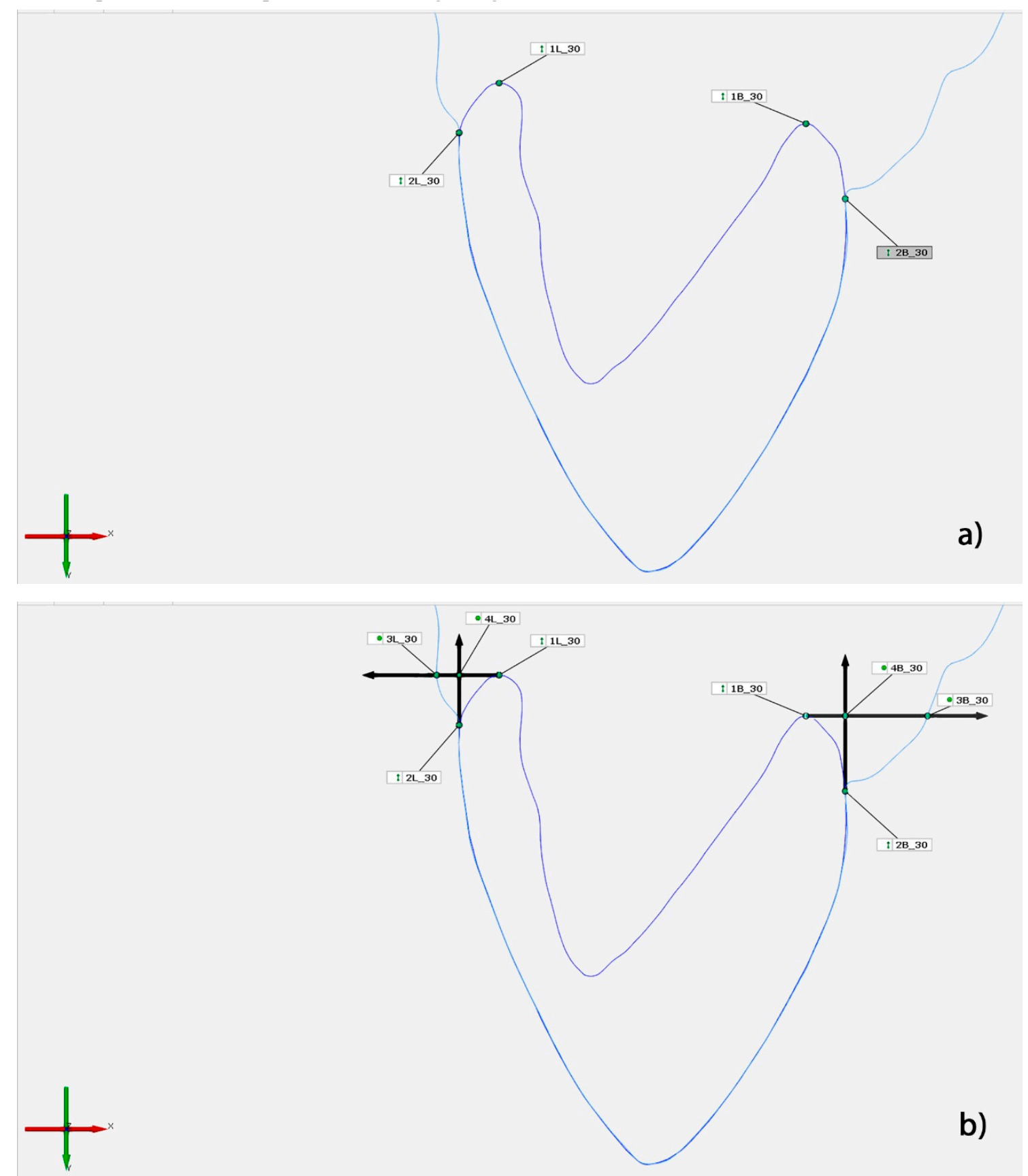

Figure 11. Cont. 


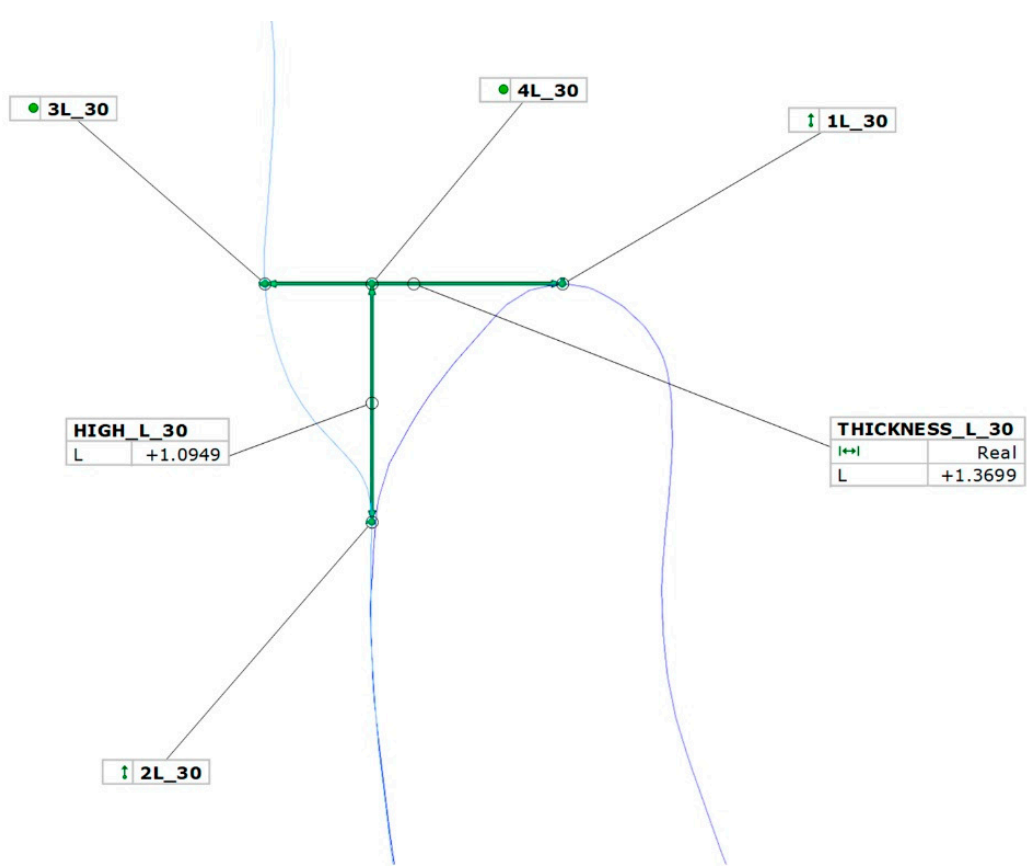

Figure 11. (a) Manual selection points 1B, 1L, 2B, and 2L. (b) Automatic creation of Lines 1B, 1L, $2 \mathrm{~B}$, and $2 \mathrm{~L}$ and the automatic creation of Points $3 \mathrm{~B}, 3 \mathrm{~L}, 4 \mathrm{~B}$, and $4 \mathrm{~L}$; (c) lingual detail of the $30^{\circ}$ provisional, with the corresponding distances. (d) Buccal detail of the $30^{\circ}$ provisional, with the corresponding distances. 


\subsection{Statistical Analysis}

All the results obtained were statistically analysed. To evaluate the differences in the variation of the gingival height and the thickness at the $30^{\circ}$ and $60^{\circ}$ angulations, a paired $t$-test was used. This test contrasts the homogeneity of the means obtained. Similarly, differences between the buccal and lingual results were compared for the same angulation. A repeated measures ANOVA model was applied with 2 intra-tooth factors (angulation and area of measurement) to better understand the mutual interactions between them. Lastly, Pearson's correlation coefficient was used to estimate the degree of linear association between variations in thickness and gingival height. The unitary impact of change in one dimension over the other was evaluated using the corresponding beta coefficient (slope) of the regression line. The significance level used in the analysis was $5 \%(\alpha=0.05)$.

\section{Results}

At buccal, the mean gingival thickness for the $30^{\circ}$ provisional was $0.941 \pm 0.530 \mathrm{~mm}$. The gum was augmented by $1.196 \pm 0.490 \mathrm{~mm}$ when there was a change to a $60^{\circ}$ provisional. Thus, the greater the angle of the prosthetic emergence of the provisional is, the greater the gingival thickness, with the mean difference in the gum being $0.255 \pm 0.381 \mathrm{~mm}$, thereby making this result statistically significant $(p=0.001 ; t$-test).

At the lingual position, the mean gingival thickness for the $30^{\circ}$ provisional was $1.107 \pm 0.494 \mathrm{~mm}$, and there was an increase of $1.145 \pm 0.394 \mathrm{~mm}$ with the $60^{\circ}$ provisional. The mean difference in the gum was $0.038 \pm 0.381 \mathrm{~mm}$. However, in this case, there was no statistically significant difference $(p=0.600 ; t$-test $)$ (Table 1$)$.

Table 1. Difference in the gingival thickness between pairs of angulations at the buccal and lingual levels: mean \pm standard deviation (median), differences between the thickness differences and the repeated measures $t$-test.

\begin{tabular}{ccccc}
\hline & & Mean \pm Standard Deviation (Median) & Difference & $p$-Value \\
\hline \multirow{2}{*}{ Buccal } & $\mathbf{3 0}^{\circ}$ & $0.941 \pm 0.530 \mathrm{~mm}(0.767)$ & $0.255 \pm 0.381 \mathrm{~mm}$ & $0.0011^{* *}(\mathrm{t})$ \\
& $\mathbf{6 0}^{\circ}$ & $1.196 \pm 0.490 \mathrm{~mm}(1.143)$ & $(0.161)$ & $0.600(\mathrm{t})$ \\
\hline \multirow{2}{*}{ Lingual } & $\mathbf{3 0}^{\circ}$ & $1.107 \pm 0.494 \mathrm{~mm}(1.040)$ & $0.038 \pm 0.381 \mathrm{~mm}$ & $(-0.058)$ \\
& $\mathbf{6 0}^{\circ}$ & $1.145 \pm 0.394 \mathrm{~mm}(1.125)$ &
\end{tabular}

The differences in the buccal and lingual results show that the gingival thickness depends on specific changes in the emerging prosthetic angle in the provisional $(p=0.012$; test $\mathrm{F})$, but this dependence is a particular feature of the area where the measurement was carried out $(p=0.022$; test F). It was shown that in buccal, a $60^{\circ}$ provisional suggests a greater gingival thickness than a $30^{\circ}$ provisional, whereas in lingual, this difference is inconsequential. (Figure 12).

In relation to the gingival height, at the buccal side, the mean difference of both angulations was registered as a decrease of $0.262 \pm 0.246 \mathrm{~mm}$, which is statistically significant ( $p=0.001$; $t$-test). The gingival height means for the $30^{\circ}$ provisional were $0.519 \pm 0.389 \mathrm{~mm}$ and decreased to $0.257 \pm 0.210$ $\mathrm{mm}$ when there was a change to a provisional with greater angulation. Hence, the greater the emergence profile angle of the provisional, the greater the shift of gingival height towards the apical direction, thereby reducing the distance between the gingival margin and the margin of the preparation. 


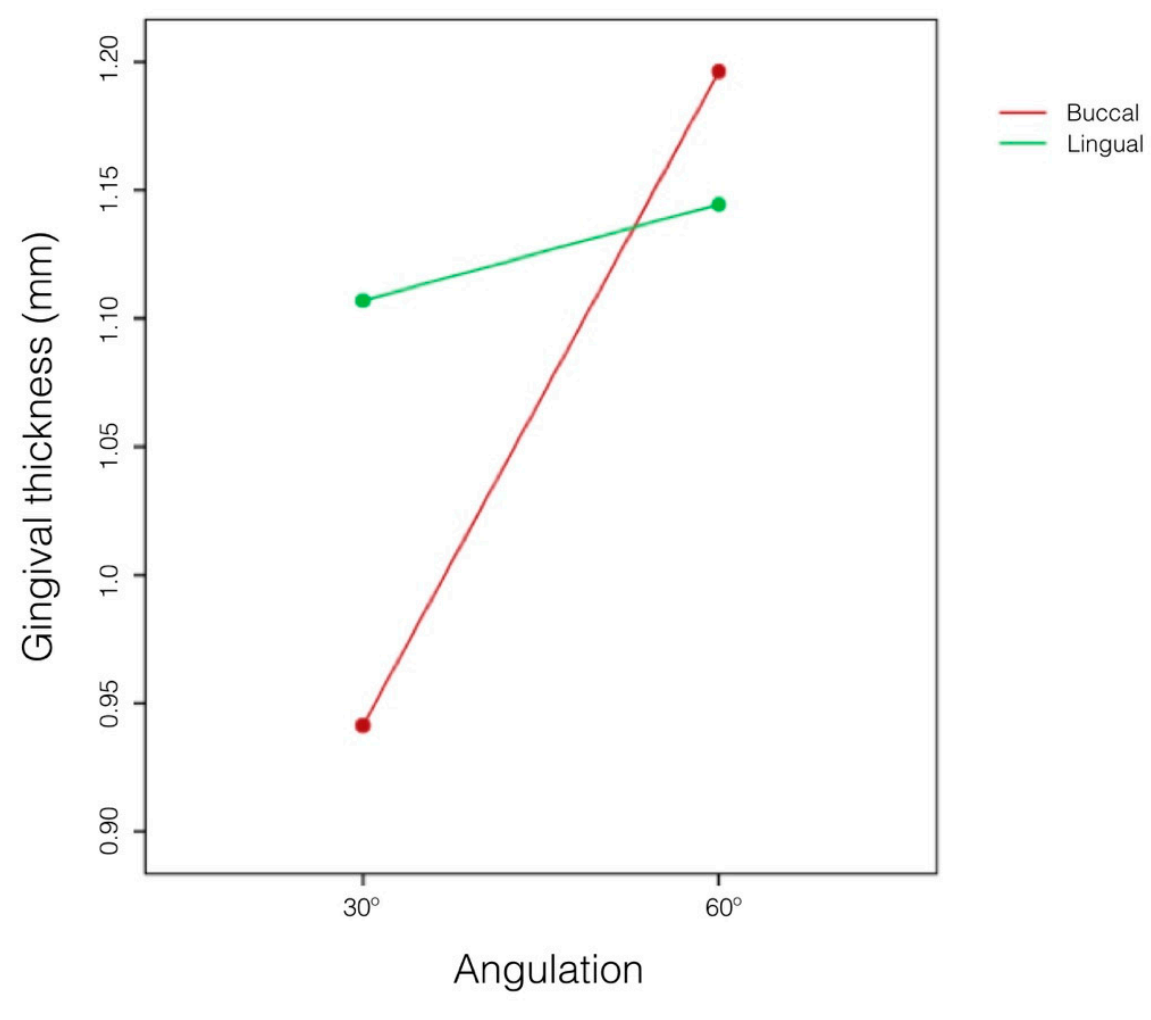

\begin{tabular}{cc}
\hline & $p$-Value \\
\hline Angulation & $0.012{ }^{*}$ \\
Measurement point & 0.682 \\
Interaction & $0.022^{*}$ \\
\hline${ }^{*} p<0.05 ;{ }^{* *} p<0.01 ;{ }^{* * *} p<0.001$.
\end{tabular}

Figure 12. Difference in gingival thickness according to a change in the emerging prosthetic angle of the provisional and point of measurement: results of test $\mathrm{F}$ based on the repeated measures ANOVA model.

In lingual, the same effect occurs, and the mean difference in gum reduction is greater (from $0.390 \pm 0.279 \mathrm{~mm}$ ) and also statistically significant $(p=0.001$; $t$-test) (Table 2).

Table 2. Difference in gingival height between angulation pairs at the buccal and lingual level: mean \pm standard deviation (median) and the difference between the height differences and the repeated measures $t$-test.

\begin{tabular}{ccccc}
\hline & & Mean \pm Standard Deviation (Median) & Difference & $p$-Value \\
\hline \multirow{2}{*}{ Buccal } & $\mathbf{3 0}^{\circ}$ & $0.519 \pm 0.389 \mathrm{~mm}(0.395)$ & $-0.262 \pm 0.246 \mathrm{~mm}$ & $<0.001^{* * *}(\mathrm{t})$ \\
& $\mathbf{6 0}^{\circ}$ & $0.257 \pm 0.210 \mathrm{~mm}(0.207)$ & $-0.211)$ & $<0.001^{* * *}(\mathrm{t})$ \\
\hline \multirow{2}{*}{ Lingual } & $\mathbf{3 0}^{\circ}$ & $0.751 \pm 0.426 \mathrm{~mm}(0.670)$ & $-0.390 \pm 0.279 \mathrm{~mm}$ & $(-0.334)$ \\
& $\mathbf{6 0}^{\circ}$ & $0.361 \pm 0.269 \mathrm{~mm}(0.329)$ & ${ }^{*} p<0.05 ;{ }^{* *} p<0.01 ;{ }^{* * *} p<0.001$.
\end{tabular}


For the comparison between the buccal and lingual levels, we can see that gingival height also depends on a specific change of angle in the provisional $(p<0.001$; test $F)$, but this dependence is a particular feature of the area where the measurement was carried out $(p=0.064$; test F). It was shown in the lingual area that changing from a $30^{\circ}$ provisional crown to a $60^{\circ}$ crown suggests a greater reduction in the gingival height than that in the buccal area (there is greater displacement in the apical direction) (Figure 13).

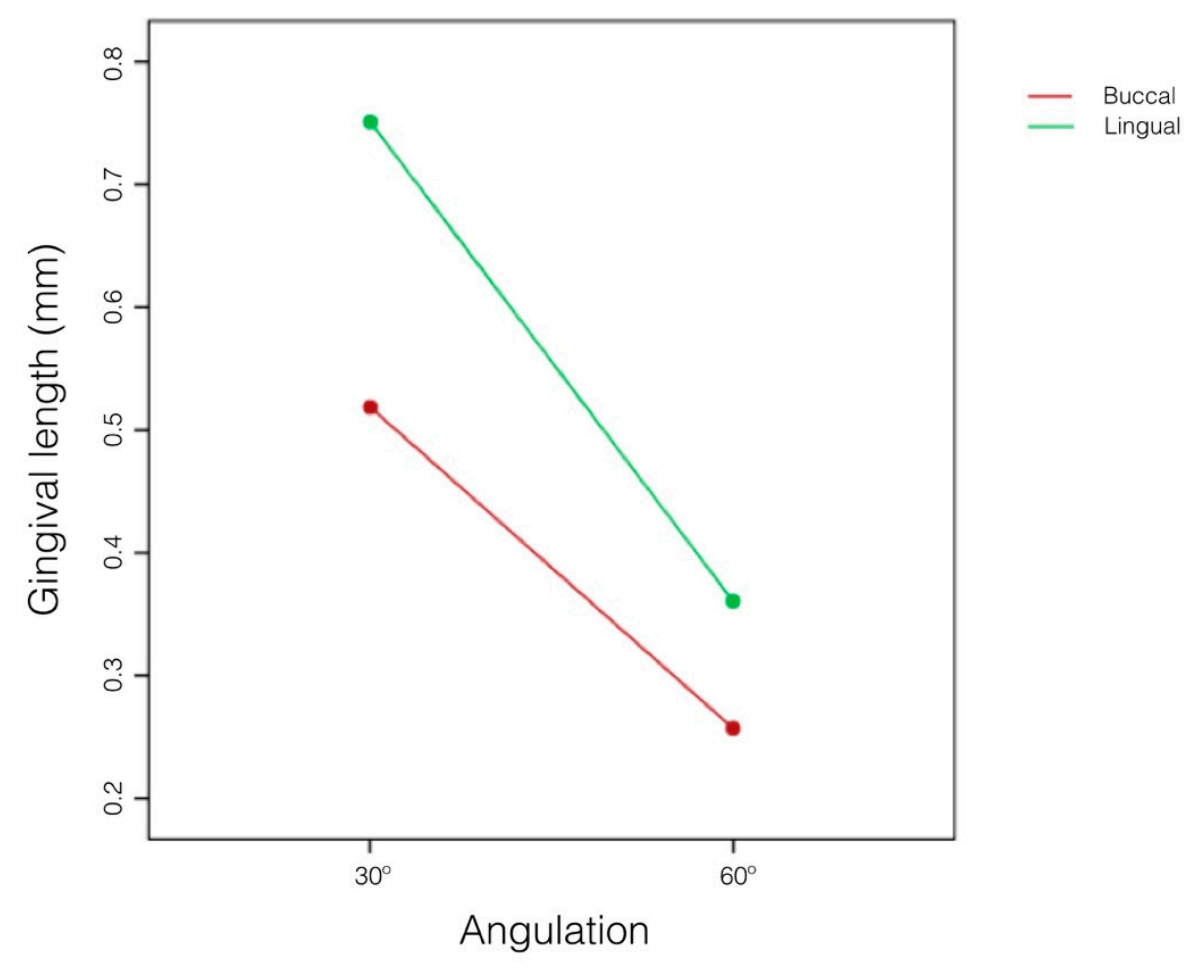

\begin{tabular}{cc}
\hline & $p$-Value \\
\hline Angulation & $<0.001^{* * *}$ \\
Measurement point & 0.061 \\
Interaction & 0.064 \\
\hline
\end{tabular}

${ }^{*} p<0.05 ;{ }^{* *} p<0.01 ;{ }^{* *} p<0.001$.

Figure 13. Differences in gingival height according to changes in the emerging prosthetic angle of the provisional and point of measurement: results of test $\mathrm{F}$ of the repeated measures ANOVA model.

An increase in the emergence profile angle of the provisional significantly diminished the gingival height and significantly increased gingival thickness. The Pearson's correlation coefficient $(r=0.636)$ is moderately high and significant ( $p=0.001$; Pearson) (Figure 14). However, as we can observe in the point cloud, for greater gingival thickness gains, the impact of the gingival height change on the same restauration is less notable $(r=0.379)(p=0.0420$; Pearson) (Figure 15). 


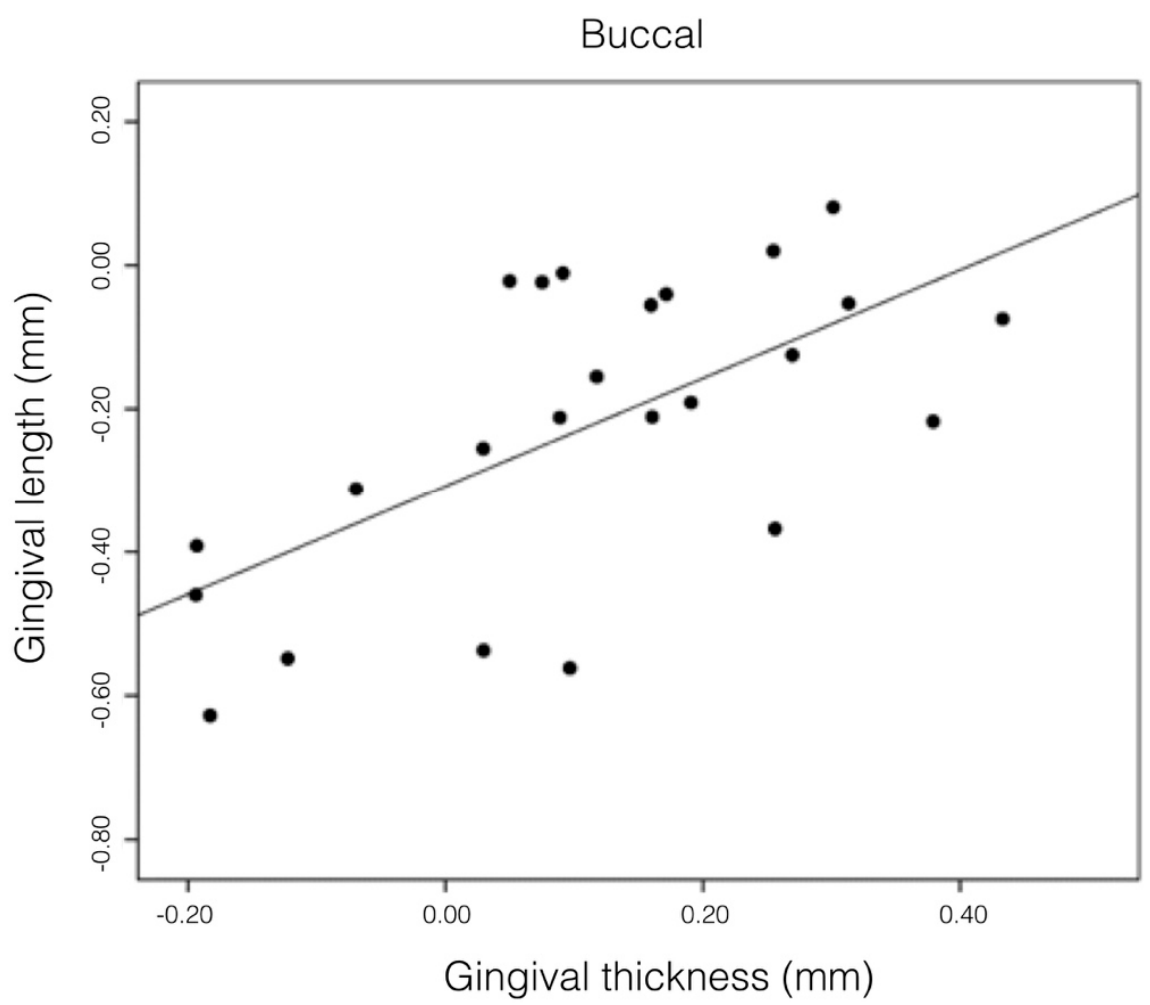

Figure 14. Correlation between an increase in thickness and a height reduction in the gum (Buccal). Pearson's $\mathrm{r}=0.636(p=0.001)$.

Lingual

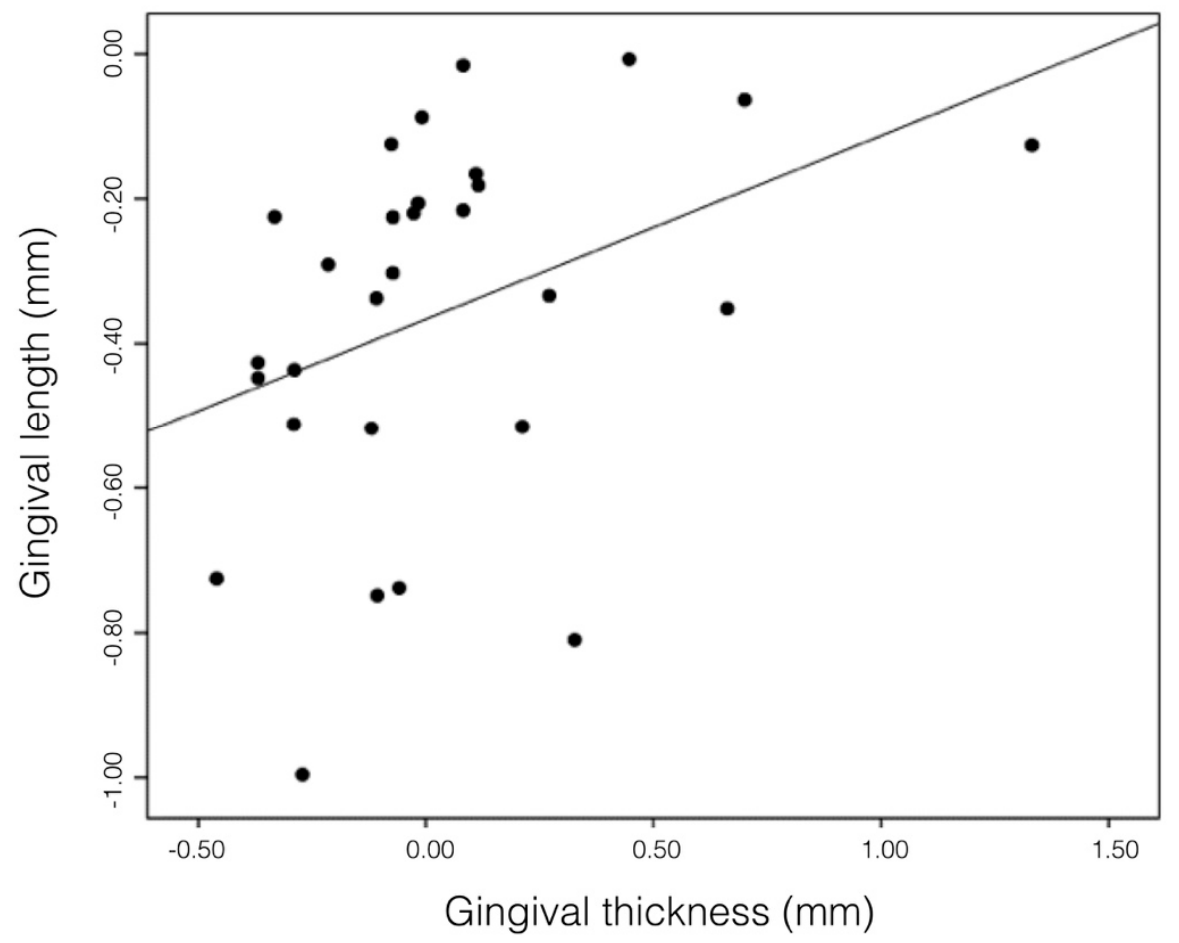

Figure 15. Correlation between the increase in thickness and height reduction in the gum (Lingual). Pearson's $r=0.379(p=0.042)$. 


\section{Discussion}

The measurement of soft tissues is receiving greater attention in the evaluation of treatment results. The volumetric analysis of oral tissues has evolved from visual inspection to more advanced techniques such as CBCT and, more recently, intraoral scanners. These instruments have, to a large extent, replaced conventional dental impressions and have facilitated the CAD/CAM process in prosthodontic treatment, as well as in orthodontic planning. In the research sphere, this technique has attracted much attention as an objective volumetric measurement method for evaluating changes in both soft and hard tissues after surgery [13-15].

In the technique described above, the provisional crown plays a significant role by offering registered responses of the soft tissues and the emergence profile; these responses can be exactly reproduced in the final restoration in an analog [13] or digital [12] manner and remain stable over time. The physiological explanation for this increase in gingival tissue is that the healing of the tissues after BOPT preparation continues under the same wound-healing mechanisms [14]. In this sense, the first provisional made in the clinic with an angle of approximately $45^{\circ}$ remained cemented for 8 weeks to attain complete maturation of the tissues. In this stage, new blood vessels are created, and fibroblasts and myofibroblasts of the degranulation tissue grow and occupy the space created by the rotatory curettage. Then, there is a contraction of the myofibroblasts around the tooth; furthermore, thanks to the conical dental preparation, a migration of the soft tissues towards the crown occurs (from the area of greatest diameter (apical) to the area of the smallest diameter (coronal)) [16,17]. This stage has been described as one where tissue growth takes place via a transduction mechanism [18,19]. The fibroblasts of the connective tissue detect mechanical stimuli (mastication, pressure from the provisional, labial pressure when speaking, etc.) in their extracellular matrix; these stimuli are then converted into chemical information that stimulates cellular growth and proliferation [18].

The clinical experience of BOPT reported in the literature has established that this technique increases the thickness of gingival tissue and enhances the stability of the soft tissue in the mediumand long-term compared to other classical preparations with finishing lines [5,7,8] (Figures 16-20).

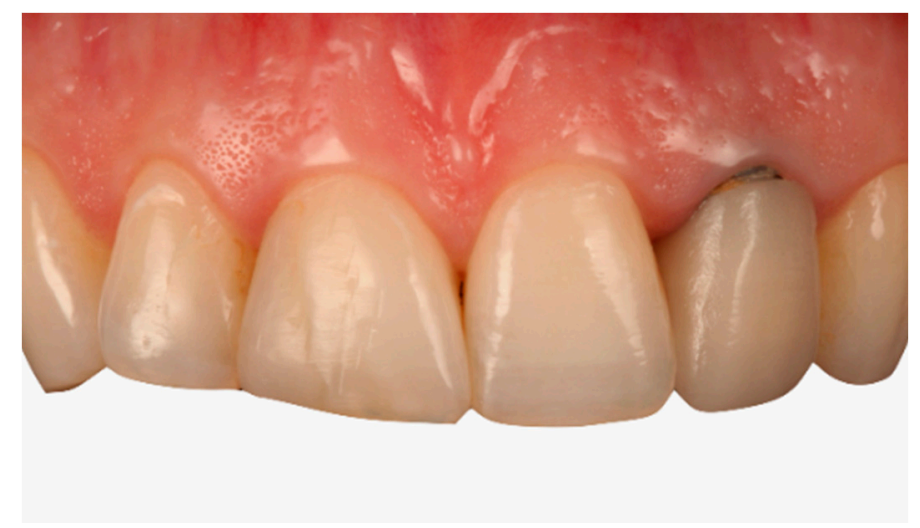

Figure 16. Retreatment of a fixed prosthesis with the BOPT technique. Initial pretreatment situation (Front view). 


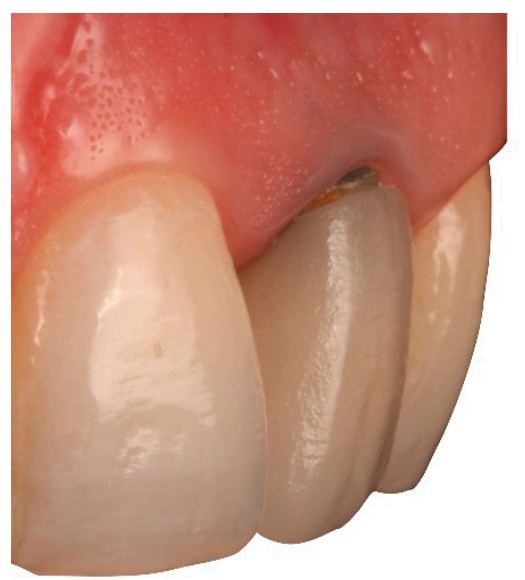

Figure 17. Retreatment of a fixed prosthesis with the BOPT technique. Initial pretreatment situation (Lateral view).
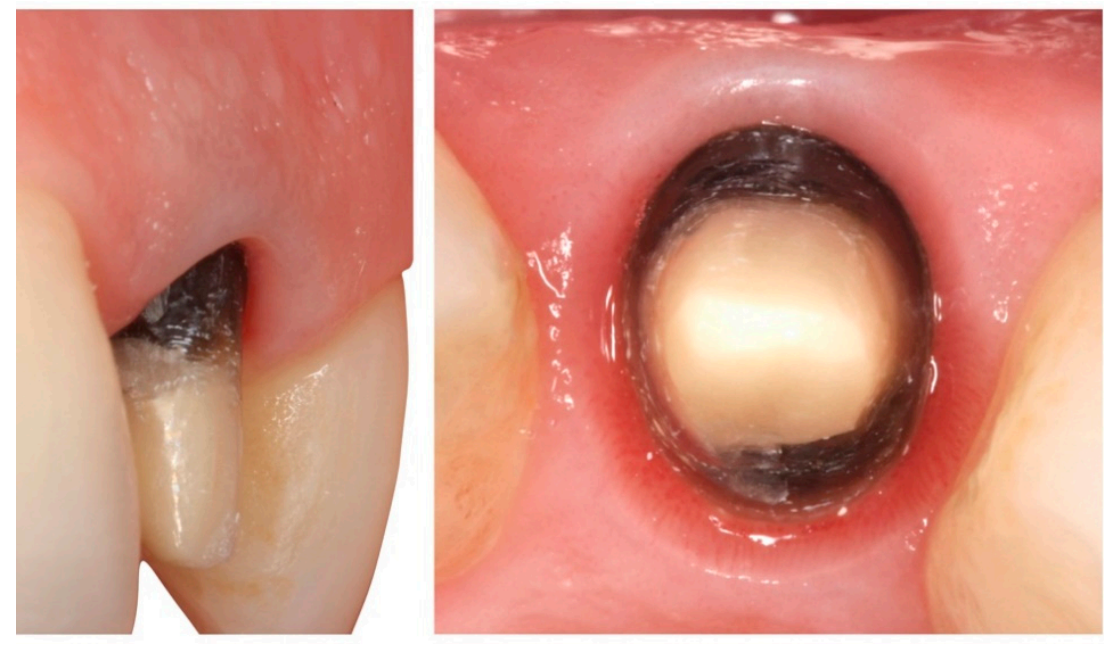

Figure 18. Gingiva after perioperative treatment with BOPT.

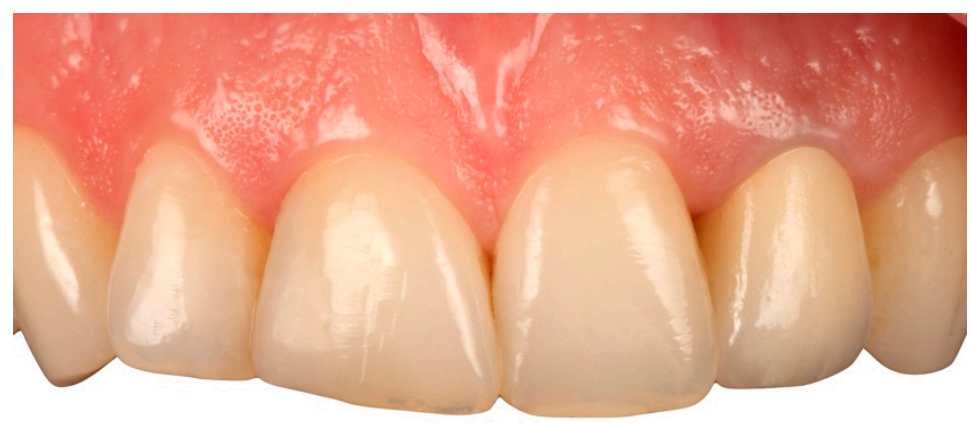

Figure 19. Situation after treatment with BOPT (Front view). 


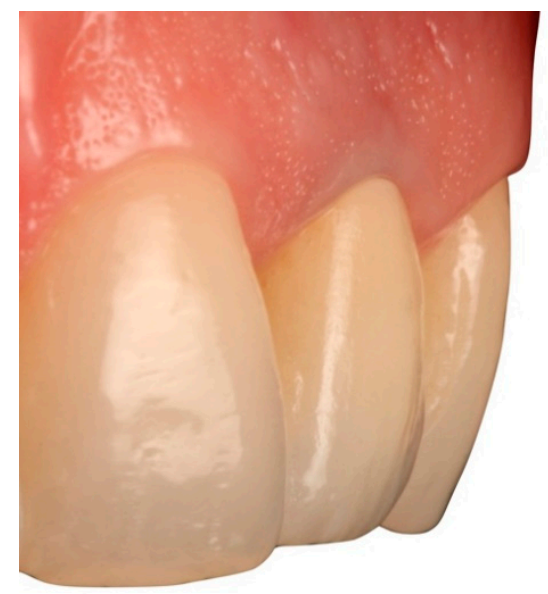

Figure 20. Situation after treatment with BOPT (Lateral view).

These conclusions are based on measurements that continue to be carried out and based on traditional methods, such as photographs, direct visual inspections, or exploration with a periodontal probe. Hence there are inherent limitations in the precision, practicality, and reduced clinical indications with current techniques. For example, Agustín-Panadero [7] and Serra-Pastor [4] used a periodontal probe to measure the gingival thickness and affirmed that this technique is not exact; hence, the conclusions of this technique are based on methods that are imprecise and subjective. Rancitelli [16] developed a reproducible method to measure the apico-coronal margin migration over time applying calibration of a well-known landmark and digital photography without using a periodontal probe. Vestibulo-lingual tissue changes were also analyzed by different authors $[20,21]$ using intraoral scanners and the superimposition of different STL files. These methods are considered reproducible techniques for measuring the thickness or volume in any research involving soft tissue evaluation [21]. This study describes a comparative analysis of an initial situation and its follow-up in terms of monitoring changes in volume. This comparative analysis made use of a digital intraoral scanner and two specific software packages, which, through the application of best fit algorithms, offer comprehensive, rapid, data analysis. The study protocol enabled the measurements offered by the models to be reproduced and provided a reliable and objective evaluation of the results, thereby reducing errors originating in the operator. Digital technologies are common in dentistry, yet they are subject to certain limitations in comparison with conventional techniques, such as the difficulty in detecting subgingival termination lines, the difficulty in registering the gingival emergence in deep implants, or the complexity of rehabilitating a full arch, despite good precision for small prostheses. These methods also require changes in work protocols, requiring a learning curve and familiarization with the techniques involved; the use of intraoral scanners to obtain a digital impression necessarily calls for experienced professionals. Furthermore, there is the need for a considerable economic outlay for the introduction of such equipment in a clinical setting [22-26]. Moreover, BOPT is a new technique in the scientific literature, and there is a need to evaluate the behaviours of soft tissues in publications with long-term follow-up prospective studies. In the literature, we found no article that follows an objective methodology like ours. Thus, it was impossible to make a comparison with our study. We consider that alignment process to be highly significant, i.e., the alignment of files with respect to the global coordinate system carried out in Phase 2. Although we believe this is a tedious and complex process, it is of paramount importance when it comes to measuring changes since the operator does not intervene at the moment of selecting points $3 \mathrm{~B}, 3 \mathrm{~L}, 4 \mathrm{~B}$, and $4 \mathrm{~L}$; instead, these points are obtained through mathematical formulations based on the previous alignment. Hence, examiner's errors were eliminated in the determination of these points, while the possible errors of alignment with respect to the global coordinate system still have the same influence over all the points.

The data obtained in the study support the hypothesis presented at the beginning of the article. Among our findings, we found that at the buccal level, a change in thickness is a better predictor 
of a change in height compared to the results at the lingual level. In the buccal zone, we found a moderately strong correlation $(\mathrm{r}=0.636)$, while in the lingual zone, the correlation was slightly weak $(r=0.379)$, despite also being significant $(p=0.042)$. The clinical implications, considering the results obtained in this study, allowed us to objectively demonstrate that if we want to displace the zenith of a tooth towards the mesial or distal direction, or if we wish to reshape a certain gum or gingival margin towards the apical or coronal direction, we have to modify the angle of the emergence profile of the prosthesis.

Therefore, if we have an anterior tooth and wish to simulate the zenith towards the distal direction with a crown, we would have to increase the emergence of the crown in distal by more than $60^{\circ}$ to a maximum of $90^{\circ}$; in mesial, we would create an angulation that is less than $30^{\circ}$; therefore, the gum in the mesial direction would move down and thin out, while in distal, it would become displaced towards the apical direction and thicken.

In cases of a recession where we need the gum to move down after BOPT (with the proviso that the bone scalloping remains healthy), we would treat the patient under BOPT and reduce the emergence of the prosthetic cervical angle, giving it an angulation of less than $45^{\circ}$, thereby allowing the gum to migrate coronally.

Thin gingiva is associated with a greater influence of recessions in orthodontic treatment [27].

There are also limitations to this study. For future studies, it will be necessary to evaluate the time needed to obtain a stable gingival margin after the cementation of a dental restoration, as there is no consensus in the literature. In all cases, the first provisional crown cemented was at $30^{\circ}$. Future studies will be necessary to analyze whether the order of the provisional cementation degree could influence gingival changes. A random cementation of $30^{\circ}$ and $60^{\circ}$ provisionals would be necessary for this task. Moreover, the influence of bone thickness is important: The thicker the bone is, the thicker the crestal labial soft tissue becomes [11].

\section{Conclusions}

Following from the findings herein, we conclude the following for BOPT restorations:

The prosthetic emergence influences the gingival tissue adjacent to the treated tooth. With greater emergences, the gum tends to thicken and migrates apically; with lesser emergences, the gum tends to thin out with a coronal displacement.

The protocol described is useful for quantifying the volume changes caused by gum variation adjacent to a BOPT restored tooth when the cervical emergence of the same is changed.

The soft tissue surrounding the restored tooth with BOPT undergoes modification as a function of the emerging prosthetic angle of the provisional restoration, thereby allowing us to plan ahead for the apico-coronal, bucco-lingual, and mesio-distal displacements of gingival tissue prior to the definitive restoration.

The clinical implication of this study can provide clinicians with the ability to displace the gingival margin of teeth treated with a complete veneer restoration, in turn allowing the thickness of the surrounding gingiva to be modified by varying the angulation of the emergence profile, thus avoiding, in many cases, the need to perform mucogingival regeneration (a connective tissue graft) or resective (coronary lengthening) surgeries.

Author Contributions: All of the authors contributed to the investigation, supervision, writing, review, and editing of the study. Study conceptualization was carried out by A.A.-G., M.F.S.-R., and R.A.-P. Data curation, data visualization, and analysis were performed by X.A.-L., L.F.-E., and J.A.P.-B. All authors have read and agreed to the published version of the manuscript.

Funding: This research received no external funding.

Acknowledgments: The authors would like to express their thanks to Alberto Alvarez García-Pumarino, Digital Dentistry Global Scientific Affairs Manager at 3M Oral Care, for his advice, guidance, and help in creating and managing the STL files and to Cesar Chust, laboratory technician, for the design and manufacture of the provisional prostheses. We thank Javier Pérez for the making of the BOPT crown illustrated by the manuscript. 
Conflicts of Interest: This manuscript has not been published and is not under consideration for publication elsewhere. We have no conflicts of interest to disclose, and all authors have approved the manuscript and agreed to its submission.

\section{References}

1. Logozzo, S.; Zanetti, E.M.; Franceschini, G.; Kilpelä, A.; Mäkynen, A. Recent advances in dental optics-Part I: 3D intraoral scanners for restorative dentistry. Opt. Laser Eng. 2014, 54, 203-221. [CrossRef]

2. Zimmermann, M.; Mehl, A.; Mörmann, W.H.; Reich, S. Intraoral scanning systems-a current overview. Int. J. Comput. Dent. 2015, 18, 101-129. [PubMed]

3. Lindström, M.J.; Ahmad, M.; Jimbo, R.; Ameri, A.; Von Steyern, P.V.; Becktor, J.P. Volumetric measurement of dentoalveolar defects by means of intraoral 3D scanner and gravimetric model. Odontology 2019, 107, 353-359. [CrossRef]

4. Serra-Pastor, B.; Loi, I.; Fons-Font, A.; Solá-Ruíz, M.F.; Agustín-Panadero, R. Periodontal and prosthetic outcomes on teeth prepared with biologically oriented preparation technique: A 4-year follow-up prospective clinical study. J. Prosthodont. Res. 2019, 63, 415-420. [CrossRef] [PubMed]

5. Loi, I.; Di Felice, A. Biologically oriented preparation technique (BOPT): A new approach for prosthetic restoration of periodontically healthy teeth. Eur. J. Esthet. Dent. 2013, 8, 10-23.

6. Agustín-Panadero, R.; Solá-Ruíz, M.F. Vertical preparation for fixed prosthesis rehabilitation in the anterior sector. J. Prosthet. Dent. 2015, 114, 474-478. [CrossRef]

7. Agustín-Panadero, R.; Solá-Ruíz, M.F.; Chust, C.; Ferreiroa, A. Fixed dental prostheses with vertical tooth preparations without finish lines: A report of two patients. J. Prosthet. Dent. 2016, 115, 520-526. [CrossRef]

8. Agustín-Panadero, R.; Serra-Pastor, B.; Fons-Font, A.; Sola-Ruiz, M.F. Prospective clinical study of zirconia full-coverage restorations on teeth prepared with biologically oriented preparation technique on gingival health: Results after two-year follow-up. Oper. Dent. 2018, 43, 482-487. [CrossRef]

9. Esposito, M.; Grusovin, M.G.; Maghaireh, H.; Coulthard, P.; Worthington, H.V. Interventions for replacing missing teeth: Management of soft tissues for dental implants. Cochrane. Database. Syst. Rev. 2007, CD006697. [CrossRef]

10. Chen, S.T.; Darby, I.B.; Reynolds, E.C. A prospective clinical study of non-submerged immediate implants: Clinical outcomes and esthetic results. Clin. Oral. Implants. Res. 2007, 18, 552-562. [CrossRef]

11. Le, B.T.; Borzabadi-Farahani, A. Labial bone thickness in area of anterior maxillary implants associated with crestal labial soft tissue thickness. Implant. Dent. 2012, 21, 406-410. [CrossRef] [PubMed]

12. Agustín-Panadero, R.; Loi, I.; Fernández-Estevan, L.; Chust, C.; Rech-Ortega, C.; Pérez-Barquero, J.A. Digital protocol for creating a virtual gingiva adjacent to teeth with subgingival dental preparations. J. Prosthodont. Res. 2019, 28, 1883-1958, PMID 30283-X. [CrossRef] [PubMed]

13. Fickl, S.; Zuhr, O.; Wachtel, H.; Stappert, C.F.; Stein, J.M.; Hürzeler, M.B. Dimensional changes of the alveolar ridge contour after different socket preservation techniques. J. Clin. Periodontol. 2018, 35, 906-913. [CrossRef]

14. Fickl, S.; Schneider, D.; Zuhr, O.; Hinze, M.; Ender, A.; Jung, R.E.; Hürzeler, M.B. Dimensional changes of the ridge contour after socket preservation and buccal overbuilding: An animal study. J. Clin. Periodontol. 2009, 36, 442-448. [CrossRef]

15. González-Martín, O.; Veltri, M.; Moraguez, O.; Belser, U.C. Quantitative three-dimensional methodology to assess volumetric and profilometric outcome of subepithelial connective tissue grafting at pontic sites: A prospective pilot study. Int. J. Periodont. Rest. 2014, 34, 673-679. [CrossRef] [PubMed]

16. Rancitelli, D.; Cicciù, M.; Lini, F.; Fumagalli, D.; Frigo, A.C.; Maiorana, C. Reproducibility of a digital method to evaluate soft tissue modifications: A study of inter and intra-operative measurement concordance. Open Dent. J. 2017, 11, 171. [CrossRef] [PubMed]

17. Agustín-Panadero, R.; Martín-de Llano, J.J.; Fons-Font, A.; Carda, C. Histological study of human periodontal tissue following biologically oriented preparation technique (BOPT). J. Clin. Exp. Dent. 2020, 12, 597-602.

18. Rodríguez, X.; Vela, X.; Segalà, M. Cutting-Edge Implant Rehabilitation Design and Management: A Tapered Abutment Approach. Compend. Contin. Educ. Dent. 2017, 38, 482-491.

19. Chiquet, M.; Gelman, L.; Lutz, R.; Maier, S. From mechanotransduction to extracellular matrix gene expression in fibroblasts. BBA-Mol. Cell. Res. 2009, 1793, 911-920. [CrossRef] 
20. Rancitelli, D.; Poli, P.P.; Cicciù, M.; Lini, F.; Roncucci, R.; Cervino, G.; Maiorana, C. Soft-tissue enhancement combined with biologically oriented preparation technique to correct volumetric bone defects: A clinical case report. J. Oral. Implantol. 2017, 43, 307-313. [CrossRef]

21. Fons-Badal, C.; Alonso Pérez-Barquero, J.; Martínez-Martínez, N.; Faus-López, J.; Fons-Font, A.; Agustín-Panadero, R. A novel, fully digital approach to quantifying volume gain after soft tissue graft surgery. A pilot study. J. Clin. Periodontol. 2020, 47, 614-620. [CrossRef] [PubMed]

22. Monaco, C.; Evangelisti, E.; Scotti, R.; Mignani, G.; Zucchelli, G. A fully digital approach to replicate peri-implant soft tissue contours and emergence profile in the esthetic zone. Clin. Oral. Implan. Res. 2016, 27, 1511-1514. [CrossRef] [PubMed]

23. Kurosaki, Y.; Mino, T.; Maekawa, K.; Izumi, K.; Kuboki, T. Digital transfer of the subgingival contour and emergence profile of the provisional restoration to the final bone-anchored fixed restoration. J. Prosthodont. Res. 2019, 63, 125-129. [CrossRef] [PubMed]

24. Li, J.; Chen, Z.; Wang, M.; Wang, H.L.; Yu, H. Dynamic changes of peri-implant soft tissue after interim restoration removal during a digital intraoral scan. J. Prosthet. Dent. 2019, 122, 288-294. [CrossRef]

25. Canullo, L.; Di Domenico, A.; Marinotti, F.; Menini, M.; Pesce, P. Soft Tissue Contour Impression with Analogic or Digital Work Flow: A Case Report. Int. J. Environ. Res. Pub. Health 2018, 15, 2623. [CrossRef]

26. Papadopoulos, I.; Pozidi, G.; Goussias, H.; Kourtis, S. Transferring the emergence profile from the provisional to the final restoration. J. Esthet. Restor. Dent. 2014, 26, 154-161. [CrossRef]

27. Borzabadi-Farahani, A. A review of the oral health-related evidence that supports the orthodontic treatment need indices. Prog. Orthod. 2012, 13, 314-325. [CrossRef]

(C) 2020 by the authors. Licensee MDPI, Basel, Switzerland. This article is an open access article distributed under the terms and conditions of the Creative Commons Attribution (CC BY) license (http://creativecommons.org/licenses/by/4.0/). 